\title{
A Community-Based Social Marketing Strategy to Prevent HIV and Fight Stigma
}

\author{
Valerio Brescia ${ }^{1}$, Myriam Caratù ${ }^{2} \&$ Giacomo Scaioli ${ }^{3}$ \\ ${ }^{1}$ School of Economic and Management, Department of of Management, University of Turin, Italy \\ ${ }^{2}$ School of Social Science and communication, Department of Communication and Social Research, University \\ Sapienza di Roma, Italy and Department of physics, University of Perugia, Italy \\ ${ }^{3}$ School of Medicine, Department of Public Health Sciences, University of Turin, Turin, Italy \\ Correspondence: Valerio Brescia, School of Economic and Management, Department of of Management, \\ University of Turin, Italy. E-mail: valerio.brescia@unito.it
}

Received: July 6, 2019

doi:10.5539/ijbm.v14n10p196
Accepted: August 10, 2019

Online Published: September 12, 2019

\begin{abstract}
There is evidence that Public Service Announcements are a crucial tool in reducing stigma and call for people to overtly seek help for their illnesses (Corrigan, Powell, Al-Khouja, 2015). In this frame, the study analyses the elements that must be present in a campaign to prevent HIV and the stigma of HIV + people, in order to redefine the essential elements in the search for effectiveness and efficiency. This campaign created for the city of Turin (Italy) represents a useful example to analyse the different phases and desired outcomes of a communication campaign. To our knowledge, this is the first European study to use data collected during a community-based activity on HIV / AIDS testing in order to build an effective communication campaign. The analysis was conducted on both quantitative and qualitative aspects of the campaign. To conduct the analysis, the literature on social marketing is analyzed in association with epidemiological and economic elements. A campaign based on community-based elements with the involvement of non-profit organizations leads to positive and innovative effects both in terms of communication and realization and relapses according to the process defined by the social marketing strategy. The statistical analysis shows a relationship between those who take the rapid test at the non-profit organization and the HIV test for the first time, demonstrating the effectiveness of the prevention campaign in the population that does not belong to the health system.
\end{abstract}

Keywords: public service announcements, community-based social marketing, HIV prevention, public health, advertising campaign, stigma

\section{Introduction}

\subsection{Introduce the Problem}

It is estimated that in Italy, similarly to other European countries, a substantial proportion (about a third) of the population is infected with HIV and not aware of its status. However, about $30 \%$ of HIV infection diagnoses are carried out in people who already present an advanced disease state (CD4 <200/MMC lymphocytes and / or AIDS-related diseases) and almost $60 \%$ of AIDS diagnoses are made in people with belated recognition of HIV infection. This phenomenon determines several negative consequences (Bert et al., 2018).

Firstly, the late-diagnosed person with HIV has no opportunity to start antiretroviral therapy within the optimal time frame and also presents a higher risk of reaching a full-blown phase of the disease plus a reduced probability of full immunological recovery once the pharmacological treatment has begun (Biancone et al., 2018).

Secondly, the lack of awareness of the state of infection can facilitate further spread of the disease. Indeed, it has been shown that people with HIV infection wholly or partially reduce the risk of transmission of the infection once they have been informed of their condition. Furthermore, there is evidence of the effectiveness of HIV prevention when addressed to people with known HIV infection (Workowski \& Bolan, 2015).

Thirdly, reducing viral load through antiretroviral therapy can also help to limit the spread of HIV infection. In fact, people aware of their serological state who actually receive an effective treatment, usually show a severely 
reduced risk of transmitting the disease to others (Liu et al., 2018; Cates Jr., Chesney, \& Cohen, 1997).

For these reasons, a series of elements provide useful tools to prevent stigma and increase access to testing. In particular, the analysis conducted focuses on communication and the elements that provide an output in terms of effectiveness, and that should be present to guarantee a real result in the territory. The study foresees a background on the elements and the process that communication in healthcare foresees connecting it to social marketing. Since social marketing in healthcare is also closely linked to the role of the community that makes up an integral part of the community, this is taken into consideration. A case study carried out in the City of Turin (Italy) provides useful elements and justifies the characteristics that the research group in collaboration with the city of Turin and a non-profit community testing community has identified. The literature does not identify cases of communication campaigns for HIV based on information gathered by the community-based service. Therefore, the analysis is innovative and closely related to identifiable elements in the community. The study can contribute to the literature on the subject of communication and analysis of outputs through community-based social marketing theory. Furthermore, the study also provides useful elements for mapping the realization process and provides a useful first case study for future benchmark in similar contexts.

\subsection{Background: Public Health Communication}

Given the high number of HIV-positive people who are still unaware of their serological status, it is considered strategic, primary and urgent to activate early identification actions able to allow early detection of these people (Sullivan et al., 2013, Bert et al., 2018a).

One of the measures that could be taken in order to increase the awareness of the population is represented by Public Service Announcements (PSAs): these usually consist of advertising tools of the social marketing communication that try to induce a behavioural change within a specific population. On these basis, it is possible that social marketing communication could be invested with a precise responsibility regarding lives saved and public health (Shi, Poorisat, \& Salmon, 2018; Hatziandreu, et al., 1995)

In general, the goal of every advertising campaign is to convey a specific message and reach a specific audience: the consumers. However, when talking about PSAs, other aspects must be considered, for example that the Key Performance Indicators (KPIs) used for the assessment of their efficacy should no longer be the commercial ones (GRP, reach etc.), but others based on the measurement of the overall impact on public health indicators deriving from the airing of the campaign. Consequently, the specific message will be a different 'call-to-action': no longer an invitation to purchase, but rather to promote a change of (wrong) social behavior or in adopting a (right) civil conscience, for instance, the use of condoms against Sexually transmitted diseases (STD) and/or the monitoring of serological status through the test taking. (DeJong, Cameron Wolf, Bryn Austin, 2001; Yadav et al., 2018).

\subsubsection{Social Marketing for Behavioral Change in the Health Programs and Psas Effectiveness}

Social responsibility is gaining its momentum in the formulation of the strategy of the organizations, at a management, behavioral and communicational level, and for many organizations it is even considered as a key differentiator and a proximity element to customers, whom are increasingly sensitive to individual and collective well-being (Carrol \& Shabanna, 2010). Welfare is not the prerogative only for companies, but also for non-profit organizations, as well as, of course, institutions and local governments (Machado, Antunes, \& Miranda, 2015).

Social marketing, as defined by Kotler, Roberto, \& Lee (2002, p. 5), has been used extensively in international health programs, especially for contraceptives and oral rehydration therapy (ORT) and it is being used with more frequency in the United States for such diverse topics as drug abuse, heart disease and organ donation (Weinreich, 2018).

In line with Kotler, Roberto and Lee (2005), some scholars tried to apply the use of social marketing principles and techniques to effective implementation of public health interventions: already in the latest $80 \mathrm{~s}$, an article (Craig Lefebvre \& Flora, 1988) discussed eight essential aspects of the social marketing process, which are here enlisted:

1- the use of a consumer orientation to develop and market intervention techniques,

2- exchange theory as a model from which conceptualize service delivery and program participation,

3 - audience analysis and segmentation strategies,

4. the use of formative research in program design and pretesting of intervention materials,

5- channel analysis for devising distribution systems and promotional campaigns,

6- employment of the "marketing mix" concept in intervention planning and implementation, 
7- development of a process tracking system,

8- a management process of problem analysis, planning, implementation, feedback and control functions

The study suggests that a wider awareness to such variables could result in more cost-effective programs that could so reach larger numbers of target audience.

On the other side, Varcoe (2004) provides a systematic way of proving the effectiveness of Social Marketing campaign, identifying five KPIs (or levels) and associated indicators of success, which are needed for the evaluation of a campaign. A campaign is dependent on a success spanning throughout all the standards of the following framework. (Fig. 1) This means that:

- failure at any level will undermine efforts to achieve subsequent levels;

- failure at later levels may be interpreted as weakness at the earlier levels, thus giving a powerful interpretation of the reasons for failure;

- however, early levels effectiveness does not guarantee for the later levels' efficiency;

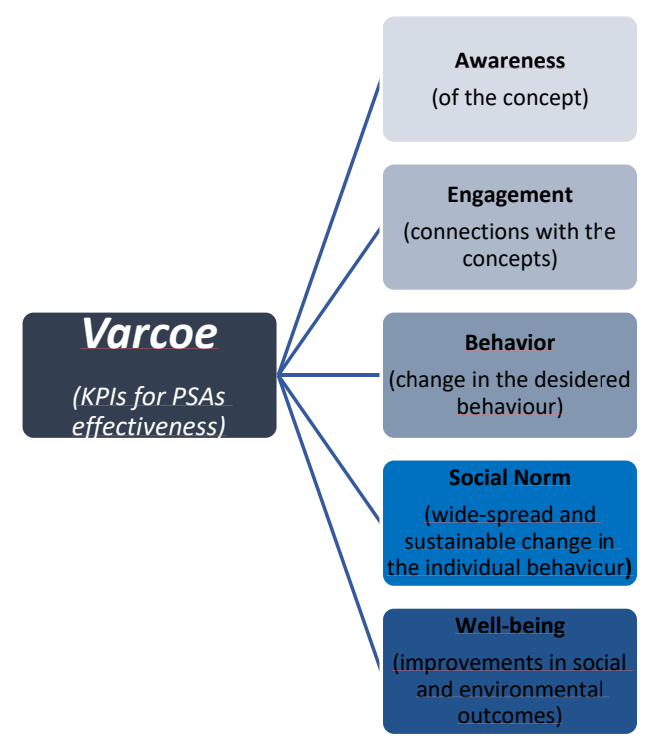

Figure 1. Rielaboration of Levels of Social Marketing effectiveness

Source: adapted from Varcoe (2004).

Coffman (2002) instead, created the Logical Model Template, which explores the Public Communication Campaigns by suggesting a framework to evaluate them:

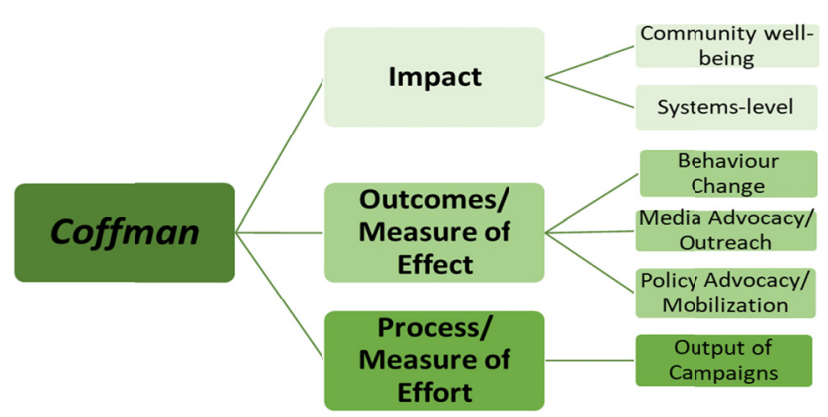

Figure 2. Rielaboration of Logical model Template

Source: adapted from Coffman (2002). 
In Craig Lefebvre \& Flora (1988) and Singh, Goyal, \& Gill, (2019), it is notable that one of the variables taken into account from the marketing discipline is the audience analysis - which is the main scope of neuro-marketing methodologies applied to the assessment of the Public Service Announcements.

There are studies that have highlighted the connection between social marketing and public policies, with reference to the tool of PSAs used for public health communications' aims: according to Harris, Ciorciari, \& Gountas (2018), there are 2 types of public health communication strategies used to support individuals in undergoing behavioral change: preventing or implementing an intervention.

A preventive communication strategy attempts to discourage individuals from undertaking harmful, risky or unhealthy behaviour, such as taking up smoking, drugs, alcohol, binge drinking, gambling, speeding and driving under the influence of various substances. Traditional preventive approaches are primarily aimed at individual behavioral change (Loss, Lindacher, \& Curbach, 2014). Public health marketing communications adopting a preventive approach are predominantly aimed at people who may be likely to consider or intend to engage in or continue certain risky behaviors (such as HIV prevention, to refer to this case study).

\subsubsection{Community-Based Social Marketing (CBSM)}

Community-Based Social Marketing (CBSM) is an approach implemented in order to achieve broadly sustainable behavior in the communities. It combines the knowledge from psychology and social marketing (Geller, 1989) to the leverage on community members' action to change behavior. CBSM is more than education: it is spurring action by a community and for a community. Community-based social marketing is composed of four steps: uncovering barriers to behavior followed by, based upon this information, a selection of the actions to be promoted; designing a program to overcome the barriers to the chosen behavior; piloting the program; evaluating it once it is broadly implemented (McKenzie-Mohr \& Smith, 1999). Social marketing emphasizes that effective program design begins with understanding the barriers people perceive when engaging in an activity (see, for example, Andreasen, 1995). Moreover, it underscores the importance of strategical delivering programs so that they target specific segments of the public and overcome the barriers to this segment's engaging in the behavior: in this sense, it is worth mentioning a recent study by Kosenko (2011) that highlights the main problems and challenges in addressing preventive measures to a specific target (in its case, the transgender community), among which there is the fear of disclosing the status itself of transgender: "Participants also reported weighing the risks and benefits of trans identity disclosures. This finding is consistent with the predictions of CPM (Petronio, 2002) and findings from other studies of stigmatized disclosures. For example, Serovich's (2001) consequences theory suggests that HIV disclosure decision-making involves a similar cost-benefit analysis and, when the individual with HIV perceives that the positive consequences will outweigh the negatives, the disclosure is more likely to occur." (Kosenko, 2011).

It is clear why disclosure can be a deterrent for people in taking the HIV test: the fear to be stigmatized by other people. However, according to Chung, \& Slater (2013), it is possible to reduce this so-called "stigma", which, according to the mainstream literature (Corrigan, 2004; Goffman, 1963; Link \& Phelan, 2001), is a sort of social rejection of individuals based on personal or social characteristics such as race, religion, and mental or physical health status - and can be a source of emotional pain, intergroup conflict, and adverse health outcomes. Chung and Slater experiment demonstrated that, in a communication campaign, the more stigmatized is the protagonist, the less is the identification mechanism of the audience in that character - identification that triggers an effective communication and reception of the message. We examine how a character's membership impacts viewers' narrative involvement in a highly stigmatized group. In particular, we explore how perspective-taking with a character, a dimension of the identification construct (Cohen, 2001), influences in-group/out-group perception. Participants viewed 1 of 2 edited versions of the film Sherrybaby, where the main character was manipulated to be relatively more stigmatized (recovering drug addict) or less stigmatized (single mother). As predicted, participants differed for perspective-taking - the highly stigmatized character corresponded to less perspective-taking. Furthermore, the mediation and moderation results lend support to the argument that perspective-taking increases perceptions of in-group belonging and are of particular importance in determining whether a narrative influences in-group/out-group perspective."

Therefore, in accordance with the abovementioned literature, the researchers of the present study have designed and implemented a campaign that

1- Adopts low-stigmatized characters to instill perspective-taking in the audience, so that the PSA message can be more effectively conveyed (as suggested by Chung \& Slater, 2013)

2- Addresses a specific target (Kosenko, 2011) of the seronegative ones, so that they can take the HIV test. 


\section{The Study: A PSA Aimed at Preventing HIV While Reducing Stigma}

In the abovementioned frame it is possible to allocate the present case-study, which is focused on a community-based social marketing campaign born from the analysis of the Italian and Regional epidemiological situation and that highlights the organizational elements linked to the service of AIDS prevention, especially regarding the HIV test offer (Tradori et al., 2017; Biancone et al., 2018).

In Piedmont (Italy) in 2016, 39 new HIV diagnoses were performed at the main centres (The SEREMI regional epidemiological center collects data from all 9 centers located in some hospitals of reference, specialized in infectious diseases in the Piedmont Region), accounting for $15 \%$ of the total cases diagnosed in the region in the same year. In the years between 2007 and 2016, the number of new diagnoses of HIV occurred in the 1st centres remained almost stable (40 cases on average per year) in contrast with a reduction of cases at the regional level. People with new HIV diagnosis performed in the 1 st centres in 2016 were predominantly men (35 out of 39) and young (21 out of 39 are under 34). A high frequency of HIV infection was seen in patients with venereal lymphogranuloma (9 out of 11), syphilis (33\%) and gonorrhea (11.4\%). In 2016, 1/4 of the new cases of HIV in Men who have sex with men (MSM) reported in the region were diagnosed in a centre for sexually transmitted diseases. Sexually transmitted diseases centres are an important public health control body that verifies the possible outbreaks of epidemics (SEREMI, 2018). During 2016, over 18,000 visits and more than 3,000 sexually transmitted infections diagnoses were reported in these centres in Piedmont. Of the 18,000, almost half were first visits. The largest number of visits and diagnoses of STDs were concentrated in Turin (15,600 visits). During 2016, in the two 1st centres which contain more service access (sexual diseases centres - Amedeo di Savoia hospital - San Lazzaro hospital) 12,000 diagnostic assessments were requested and 1,500 surgical procedures were performed.

The objective of the analysis is to identify the main elements of the communication campaigns, in order to increase the testing and use of prevention measures in Piedmont. The analysis also includes the communication aspects against HIV+ stigma, which should play a role as well-being factor in the community.

\subsection{Contents of the Campaign}

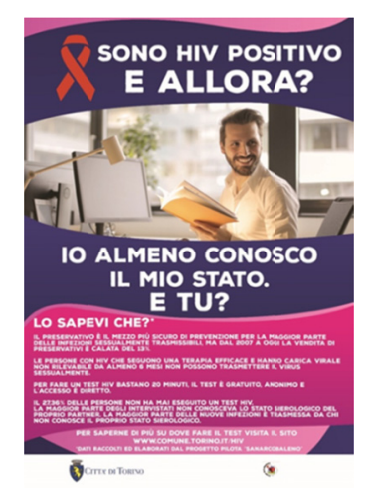

Figure 3. Poster prevention male claim City of Turin - Odv Casa Arcobaleno 2019

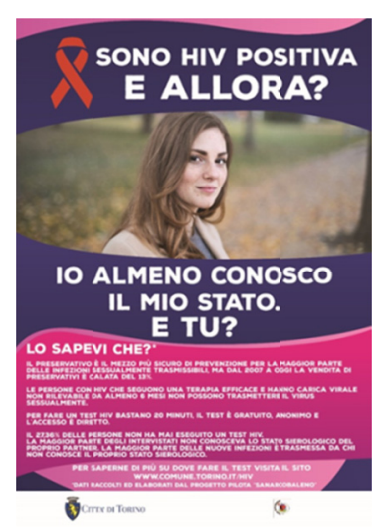

Figure 4. Poster prevention female claim City of Turin - Odv Casa Arcobaleno 2019

The communication campaign of the City of Turin was carried out through posters (Figures 3 and 4). 
Effectiveness and efficiency have been assessed following a planning and control process of the campaign (Austin \& Pinkleton, 2015). The campaign was carried out both online and with public billboards. The posters have a dimension equal to $140 \times 200 \mathrm{~cm}$ that allows their distribution in the institutional spaces scattered throughout the city in all the circumscriptions. The contents respect the theory regarding the creation of effective posters concerning visual communication (Frascara et al., 1997; Wright, 2018). The poster presents the main claim "I am HIV positive. I, at least, know my state. What about you?". The image of a boy or a girl is deliberately clean to attract attention and not to provide an incorrect interpretation that can be linked to the message. Then follows an information section. The posters' claims are divided in four essential statements, concerning both the fight against the stigma of people affected by HIV and the prevention of risky behaviors linked to the non-consideration of the partner's serological state. The following sections explain in detail each element of the poster that also were used as an online communication campaign.

\subsection{Fight Against the Stigma of HIV + People in Communication, Why Man And Female}

The HIV + and HIV + stigma prevention campaign was carried out with both male and female images. The regional data disseminated by SEREMI (2018) and the results of the community-based project already realised by the Association Odv Casa Arcobaleno in the previous year (Tradori et al., 2017, 2017a) showed that the primary cases of positivity to HIV and riskier behaviour are found in men having sex with men. However, these data could also be interpreted differently. Considering both the regional data and the data of the Organization of voluntary Casa Arcobaleno prevention and testing project, most of the users who get tested have a homosexual or bisexual orientation. Heterosexuals, and in particular women, do not get tested or they are less than men. On a social level, gender and gender-related behaviour also have a strong impact on sexual behaviour, leading to a higher risk for women (Wingood \& DiClemente, 2000). In the design phase, to increase the testing of women and heterosexuals, the campaign was carried out considering two neutral subjects (who did not clearly express their sexual orientation) to improve the number of subjects which usually have a lower culture linked to HIV testing and syphilis. The campaign does not exclude the sample that shows the higher incidence rates, thus allowing to reach new users.

\subsection{Use of Condom}

The first statement of the Poster is "the condom is the safest mean of prevention for most sexually transmitted infections, but since 2012 the sale of condoms has dropped by 13\%" can be confirmed by literature and data (Federfarma (2016). Several quantitative studies have confirmed the effectiveness of condoms in HIV prevention in both heterosexual and same-sex relationships (Weller, 1993; Varghese et al., 2002; Weller \& Davis - Beaty, 2002; Coates, Richter, \& Caceres, 2008). In particular, it is deemed to “make the difference” , especially in fear-arousing appeal campaigns (which is our case) as stated by Struckman - Johnson, \& Struckman - Johnson (1996), who investigated the effect of adding a recommendation to use condoms to a fear-arousing AIDS PSAs on subjects' intentions to use condoms and taking of free condoms. They demonstrated - interpreting their results in terms of the AIDS risk reduction model (Catania, Kegeles, \& Coates, 1990) - that, even though the recommendation had no effect on intentions to use condoms, men exposed to a fear-arousing PSA with the recommendation took significantly more condoms than men in the no-recommendation condition. Men also bought significantly more condoms than women in the recommendation condition.

Data from the National Institute of Statistics (ISTAT, 2015) indicate that the contraceptive methods mostly used in Italy are: condom (42.4 percent), pill (24.3 percent), discontinued coitus (17.5 percent), other natural methods (4.2 percent), Intrauterine Device (4 percent), the vaginal ring ( 2.1 percent), the patch ( 1.5 percent), sterilization (1.4 percent) and the diaphragm (1.2 percent). It is clear that the behaviour of the Italians must change in order to reduce the infection. According to data from the Italian Institute of Health, the increase in STDs is 1 million new infections a day, with 4,000 new cases of HIV infections per year (CNAIDS, 2016). According to Federfarma, National Federation representing over 16,000 private pharmacies affiliated with the National Health Service, a 13\% decline in condom consumption, from 2007 to 2016, means lower use of condoms in Italy compared to other European countries (Federfarma, 2016).

\subsection{HIV People under Therapy}

The second statement of the poster says "people with HIV who are on effective therapy and have an undetectable viral load for at least six months cannot transmit the virus sexually". The study conducted by Vanable et al. (2000) points out that people with HIV are afraid of infecting their partners in many cases; new therapies diminish perception and have an impact on the behaviour and serenity of individuals. The study also highlighted that the therapies do not eliminate the contagion between partners affected by HIV and non-infected partner. Waitt et al. (2018) show that mother-to-child transmission in women with a viral load reduced by therapy allows 
non-transmission to the child. The results of this study have also been confirmed as regards the infection between serum-discordant couples, also indicating the time necessary before zeroing the viral load of the subject affected by HIV (Bavinton et al., 2018; Safier \& Sauer, 2017; Woodson, 2018; McColl, Kojovic, \& Piquette Miller, 2018). The communication of this element linked to the treatment and elimination of the possible transmission between serum-discordant individuals in antiretroviral therapy thus becomes an essential element in communication towards the citizens. This is to reduce the stigma towards people affected by HIV and, at the same time, decrease the new infections through the promotion of respect and continuity of therapy in infected people.

\subsection{Organization of Testing Service in Piedmont Region and Its Effectiveness in Community Based}

The third message included in the poster refers to the possibility of carrying out the test for free in 20 minutes. Reference is made to both the time average recorded during testing, according to indications related to the type of test used, and to the average time required for withdrawal from hospital facilities. Regional Health Service (RHS) structures in Italy (following the European guidelines) that offer the HIV test must ensure: the gratuitousness of the service, the direct access and the anonymity to all the people who request it, and must provide adequate procedures to maximize the confidentiality of the outcome and information on the person who requires the test (ECDC, 2010).

Moreover, RHS structures that offer the HIV test must guarantee directly, or indirectly through the connection with specialized centres, appropriate diagnostic procedures, prevention activities, treatment and care, facilitating prompt management in the event of positivity (HIV in Europe Secretariat, 2012). The implementation of prevention interventions that provide for the rapid test in strategic contexts is indicated in order to increase the early diagnosis and reach the people that use the health services with difficulty (HIV testing in Europe, 2004; WHO, 2015). The active offer of the rapid HIV test promoted by organizations operating outside RHS (associations, third sector), must involve specialised clinical centres (infectious diseases, STD Sexually-Transmitted Diseases centres) of Piedmont Regional Health Authority (Piedmont Region, 2016). In particular, protocols and procedures relating to the following aspects must be prepared: training of personnel involved in the test offer, communication of the results of the test, sending the positive results to the centres of infectious diseases for the confirmation of the results (validation of the invalid and positive results) and the management and disposal of biohazardous health waste. All RHS practitioners who come into contact with people who have sexual behaviour at high risk of HIV infection should systematically propose the HIV test. All people who apply to regional TSI centres must be actively and systematically offered the HIV test. The HIV test must also be actively offered to all persons who have suffered sexual violence, according to the criteria, timing and modalities of the protocols for the provision of post-exposure prophylaxis.

Finally, HIV test must be actively and systematically offered to all people:

o who have made use of, or even occasionally use injective and non-injective drugs;

o who are in charge of Public Services for Addictions, or Drug Addiction Service;

o who originate from countries with high HIV endemic (prevalence> $1 \%$ - a reference to the UNAIDS estimates), at the first opportunity in which they turn to RHS structures or to services dedicated to the protection of their health, regardless of the reported risk behaviour;

o presenting symptoms suggestive of acute HIV infection;

o presenting diseases included in the definition of AIDS or associated with HIV infection (the test offered in these cases is strongly recommended and must be systematic);

o presenting a condition or pathology whose management may be influenced by knowledge of the HIV serological status.

The HIV test must also be offered to all pre-conceptional women, at the time of pregnancy and subsequently during gestation if exposure to risk occurs (the test offer in these cases is strongly recommended and must be systematic).

The HIV test must be offered to the partners of pregnant women or who intend to start a pregnancy; in these cases, it is strongly recommended and must be systematic. Health care personnel assisting women in childbirth should check that the HIV test has been performed during pregnancy. If this has not happened, the emergency procedure must be offered in order to be able to make the appropriate decisions on the prophylaxis measures to be implemented, including the procedures for carrying out the childbirth. The HIV test is mandatory for all blood or blood component donors, organs, tissues and cells. The HIV test must be systematically offered to all persons 
with accidental percutaneous exposure (cutting, tip injuries, mucosal contamination and / or non-intact skin), to potentially infectious material according to the criteria, timing and modalities foreseen by the protocols for post-exposure to HIV prophylaxis.

The 4th generation immuno-metric tests (I level test) are the tests of choice indicated for the diagnosis of HIV infection in particular for cases of suspected acute or recent infection and if the test is performed for organ donation and of blood components. Moreover, the release of newer 4.5 - generation rapid tests consented to reach a specificity and a positive predictive value of about 100\% (Bert et al., 2018a). Immuno-metric tests that look for both antibodies against hiv1 and hiv2 and that are sensitive to the subgroup or hiv-1 must be used. Positive or doubtful results at I level tests should always be confirmed by Western Blot / Immunoblotting (II level or confirmatory test) and / or HIV RNA. If the results of the serological tests are not conclusive, the research of HIV RNA can be carried out at the reference laboratories. Laboratories carrying out anti-HIV serological tests should preferentially work on a mother test tube, include internal quality control within each session and participate in an external quality assessment program (VEQ) on a regional, national or international basis.

Regarding the interpretation of the result and reporting of the serological test for HIV antibodies (Piedmont Region, 2016):

- The negative result of the first level immuno-metric test (screening) indicates the absence of HIV infection if performed 3 months after the last exposure potentially at risk;

- In case of reactivity of the first level immuno-metric test, the Western Blot and / or HIV RNA confirmation test (II level test) always must be performed;

- In the case of discordant results (test I reagent level / western blot / immunoblot negative or undetermined) the HIV RNA execution is indicated by sending the sample to the reference laboratories. In the case of suspected acute HIV infection, the test of choice is HIV RNA ("window" phase);

- The report must include the result of the test as "positive" / "reactive" or "negative" / "non-reactive" together with information on the method used to perform the tests (ELISA, chemiluminescence, etc.);

- $\quad$ Reporting of a "positive" / "reactive" result should only be performed after confirmation of the result on the first level immuno-metric test with the western blot / immunoblotting and / or HIV RNA confirmation test;

- Test reporting times should normally be within one week;

- Each positive / reactive report for HIV must be delivered exclusively to the person to whom the examination refers to, with post-test counselling and contact with the Infectious Diseases Centre for patient delivery.

Concerning the rapid tests for anti-HIV antibodies:

- The operator (health and otherwise), appropriately trained, who offers the rapid HIV test must perform the assessment of the risk of acquiring the infection of the person undergoing the test;

- The result of the rapid HIV test must be communicated verbally during an interview and must be contextualised on the basis of the assessment of the risk of acquiring the HIV infection of the person undergoing the test. When the person has reported dubious exposures in the three months prior to the execution of the test, the operator must propose sending the person to a centre of infectious diseases and possibly repeat the test 3 months after the last exposure;

- The positivity of a rapid test must always be confirmed with other reference methods, according to the procedural algorithms foreseen for the conventional screening test (1st level);

- The reactive result of the test can be interpreted as "preliminary positive", but always requires the execution of a confirmation test on the blood sample and the taking charge of the person by the centre of infectious diseases.

\subsection{The Use of Institutional Site of City of Turin on the Campaign and Diffusion}

The use of the institutional site is the most recognized feature for the transmission of information and the veracity of the data, as perceived by the population of the City of Turin (Biancone et al., 2016).

\subsection{The Cost of the Campaign and the Time}

The City of Torino (Italy) announced in July 2018 the launch of a communication campaign aimed at fighting the stigma of HIV + people and promoting and encouraging testing. The Odv Casa Arcobaleno Association 
responded to the competition by winning it. The total estimated cost of the call for tenders was $1200 €$ with the request for planning and printing the communication campaign. The cost of the design was $€ 550$, while the cost of printing the communication campaign to be posted on the streets was $€ 550$. The actual value presented in the social report of the Association (Brescia \& Iannaci, 2019) and absorbed by the Public Administration was calculated according to a standard redefinition of the Study Group for the Social Report (GBS, 2013) and Piedmont method (Rainero \& Brescia, 2016). The Association co-funded the communication project for the City of Turin. In particular, out of 2,131.14€, 1,200€ were tied up for the communication campaign for the City of Turin, the Association has committed and used $€ 240$ as co-financing, to which $€ 255.77$ were added for not foreseen expenditure in location of project planning necessary to carry out the activity in terms, and according to the times in which the City of Turin has foreseen the launch of the communication campaign (Figure 5).

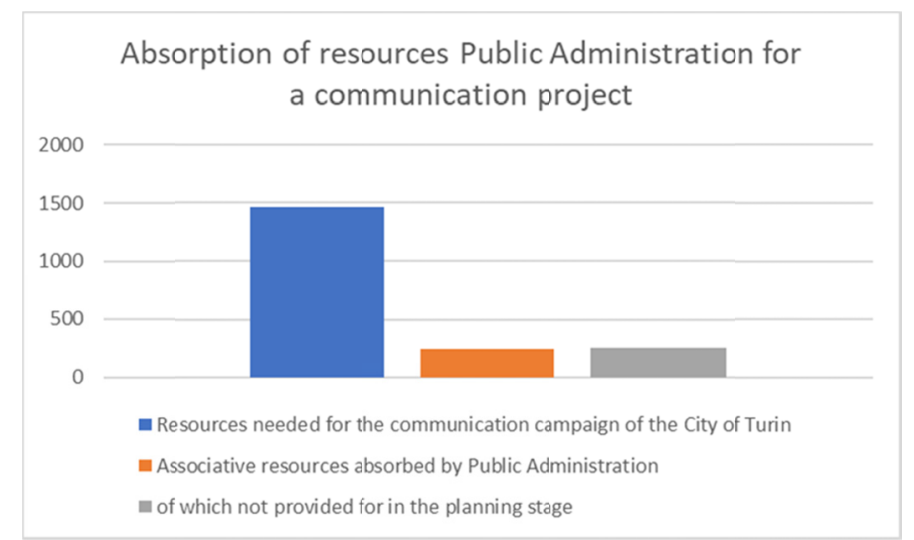

Figure 5. Redefinition of creation value from the Social Balance (Brescia \& Iannaci, 2019)

Currently, the private costs for prevention are not quantified and include extraordinary expenses for specialists examinations, laboratory tests (such as HIV or the Pap-test, widely practiced privately), insurance complementary health services (which concern 9 million Italians and often offer preventive services), preventive dental visits, examinations carried out in the context of health surveillance of workers (Signorelli et al., 2016). Therefore, the evaluation of the campaign and the publication of the necessary expenditure is singular. The implementation by an association has reduced costs by shifting a large portion of the design to voluntary work. The data collected in the prevention and testing project carried out in the municipal area has was also useful to precisely identify the need and type of primary messages for the reference context by increasing the accuracy of the communication.

\section{Method}

In the case study analyze the main characteristics and context of the case study of campaigned realized in the City of Turin (Benbasat, 1984, Yin, 1994). The analysis considers context of the Piedmont Region and it is also significant thanks to previous analyzes always conducted in collaboration with the various partners (Tradori et al., 2017, 2017a) and provides. The data were collected during the implementation of the experimental project realized by No Profits Odv Casa Arcobaleno in agreement with the Arcigay Association "Ottavio Mai", the City of Turin and the Piedmont Region with useful elements to define an effective communication campaign. To ensure the validity of case studies, data were collected through the presence and direct observation and presence during the internal meetings aimed at analyzing the case study. Furthermore, the triangulation guarantees the results relative to the collected elements. The data are original, and the case study and the analyzed sample presents elements that cannot be modified (Silverman, 2005). The flanking of qualitative and quantitative analysis around the case guarantees the veridicity of what is expressed and analyzed (Glasser \& Stauss, 1967). External validity is possible because of the characteristics related to the document. The generalization of research results in similar contexts is possible through the analysis of the elements (Eisenhardt, 1989). The analysis and the treatment were conducted taking into consideration also reliability as the scholars usually would need to do when talking about case studies. "Reliability" refers to the absence of random error, enabling subsequent researchers to arrive at the same insights if they conducted the study along the same steps again (Denzin \& Lincoln, 1994). Transparency and the possibility of replicating research allow and guarantees this aspect. The narrative collected during the study and the methodological approach of analysis and the replication of the case study analysis (Leonard-Barton, 1990). The project carried out by the association aimed to increase the early diagnosis of HIV and syphilis and, at the same time, was designed to sensitize the population about sexually 
transmitted infections and stigma towards the HIV + community. A risk assessment questionnaire was administered to the population that requested it, with free access by the volunteers of the abovementioned associations. The questionnaire was composed by 14 questions and aimed to collect socio-demographic data useful for the communication campaign. The questionnaire was built to identify the main Global AIDS Response Reporting criteria, according to the UNAIDS guidelines (2017) and ECDC (2009) guidelines on the definition of the structure. The risk assessment questionnaires collected by the volunteers allowed the definition of social and statistical elements useful for highlighting some essential features for the communication campaign (Oppenheim, 2000). The Association defined a protocol to guarantee accessibility, gratuity, and anonymity. The medical staff provided with the test and the counselling, while the acquisition of the risk assessment data was collected by the volunteers who informed the user about the type of the offered test and the process following the confirmation test at the reference hospital in case of reactivity of the test. The method of supply and route of administration of the test follows the international guidelines (ECDC,2010; WHO, 2010, 2015, 2015a; 2018; EACS, 2017; Lazarus et al., 2013) and is consistent with regional guidelines. The questionnaire is divided into 3 sections, the first collects demographic characteristics of the subject, the second section investigates the risky behaviours and the type of sexual relations occurred in the last 12 months, while the last section investigates the behaviour of the subject towards possible HIV + partners (Breveglieri, Bosa, \& Brescia, 2017). The quantitative analysis of the variables recorded through the interview of the users by volunteers and doctors was carried out during the year 2017. All analyses were performed via STATA V.14,2 (Stata Corp., College Station, Texas, USA, 2013) with a p $<0.05$ considered significant for all analyses. The analysis was conducted through linear regressions to evaluate predictors of frequency of rapid HIV tests in the last 12 months and predictors of the decision to have sex (including oral) with a partner knowing that he/she is HIV +. Moreover, a descriptive analysis helps to understand the characteristics of the sample. The analysis of the elements of the campaign is qualitative and focuses on the messages that can be connected with the literature and statistical results previously provided. The obtained results were compared and confirmed by the volunteers and the doctors of the Association who administered the questionnaire throughout the year, also expanding, through a semi-structured interview, the possible topics to be addressed and understood in the communication campaign, together with some limits related to incorrect knowledge of the users. The importance of the characteristics of the communication campaign is discussed by highlighting the main aspects and providing useful insights for future perspectives (Niederdeppe et al., 2006). The reference context is closely linked to the social identity theory and allows to immediately identify the characteristics to be analysed to combat the stigma (Chung \& Slang, 2013). The study allows to redefine the theory related to public communication and provide important elements for future prevention communication as defined by Cho \& Salmon (2007). Moreover, the study highlights the social and economic impact provided by the association in the implementation of the communication campaign commissioned by the City of Turin. The campaign output according to the literature on social marketing is evaluated through various elements linked to integral parts of the communication campaign. The elements that make up the campaign and which are analyzed are themselves part of the application of the theory aimed at maximizing efficiency and effectiveness. I also consider the costs and the epidemiological elements of the sample used as a reference for the idealization and the relapse analysis. The campaign is therefore part of the results of the research conducted. The relationship between KPIs, costs and elements of output is therefore represented.

\section{Discussion}

\subsection{Sample}

The sample is mainly made up of subjects under the age of 35 , as shown in table $1.84 \%$ are men, $16 \%$ are women. $87.56 \%$ are Italian, while $12.44 \%$ are of other nationalities. $15.42 \%$ of the respondents declared to be heterosexual, $62.69 \%$ homosexual or lesbians, $4.98 \%$ queer, $16.42 \%$ bisexual and $0.5 \%$ others. 
Table 1. Sample

\begin{tabular}{|c|c|c|c|}
\hline Item & Range & Number & percentage \\
\hline \multirow[t]{10}{*}{ Age range } & $18-23$ & 40 & $19.90 \%$ \\
\hline & $24-29$ & 49 & $24.38 \%$ \\
\hline & $30-34$ & 42 & $20.89 \%$ \\
\hline & $35-40$ & 17 & $8.46 \%$ \\
\hline & $41-45$ & 20 & $9.95 \%$ \\
\hline & $46-50$ & 13 & $6.48 \%$ \\
\hline & $51-55$ & 10 & $4.97 \%$ \\
\hline & $56-60$ & 3 & $1.49 \%$ \\
\hline & $61-65$ & 3 & $1.49 \%$ \\
\hline & $>65$ & 4 & $1.99 \%$ \\
\hline Gender (male) & & 170 & $84,58 \%$ \\
\hline Italians & & 176 & $87.56 \%$ \\
\hline \multirow[t]{5}{*}{ Sexual orientation } & Heterosexual & 31 & $15.42 \%$ \\
\hline & Homosexual & 126 & $62.69 \%$ \\
\hline & Queer & 10 & $4.98 \%$ \\
\hline & Bisexual & 33 & $16.42 \%$ \\
\hline & Other & 1 & $0.5 \%$ \\
\hline Hiv and/or syphilis test in the past & & 146 & $72.64 \%$ \\
\hline \multirow[t]{3}{*}{ Preference of testing asset } & Community based context & 116 & $57.71 \%$ \\
\hline & Hospital & 5 & $2.49 \%$ \\
\hline & both & 80 & $39.80 \%$ \\
\hline \multirow[t]{6}{*}{ Number of sexual partners in the last 12 months } & None & 5 & $2.5 \%$ \\
\hline & 1 & 28 & $14 \%$ \\
\hline & $2-10$ & 129 & $64.5 \%$ \\
\hline & $11-20$ & 1 & $0.5 \%$ \\
\hline & $21-50$ & 32 & $16 \%$ \\
\hline & $>50$ & 5 & $2.5 \%$ \\
\hline
\end{tabular}

\subsection{Characteristics of the Sample}

$27.36 \%$ of the sample never took an HIV and syphilis test before, while $72.64 \%$ had at least once. However, the data shows who accessed to the first test during the first year of experimentation inside the Association Odv Casa Arcobaleno. Most of the users who decided to undergo to the test have then repeated the check of their state of health, in particular 30.35\% of users have repeated the HIV and Syphilis test in the last year, while 10.95\% of users repeat the test every two years. It can be said that users who turn to the service are accustomed to carrying out the test periodically. A total of $24.38 \%$ never took a test before, and the first was done at the rapid test association service. The sample had an average number of partners in the last year (considering from the time of the administration of the test and the questionnaire) equal to $1(14 \%)$, from 2 to $10(64.5 \%)$, from 11 to 20 $(0,5 \%)$, from 21 to $50(16 \%)$, over $50(2.5 \%)$. Only $2.5 \%$ of the sample did not have sex in the last year. Higher is the age of users, higher is the frequency of people who have already tested in the past $(\mathrm{p}=0.002$ with a standard error equal to 0.3494 and R2 $=0.0469$ ). This could be due to the awareness campaigns of 1998 (the first AIDS campaign in Italy) and November 30, 1991 (AIDS and HIV prevention campaign with the use of Wolf Alberto that caused scandal among the public opinion) (Frati \& Cordone, 2002). Spending and propaganda for the reduction of the fight against HIV is also linked to the discovery of new therapies. There is a correlation between those who took the HIV test before accessing the service and the number of partners they had in the last year $(p=0.001$ coef. $=0.0054 \mathrm{R} 2=0.063)$. This shows that those with multiple partners have already tested. There is a difference between those who did test and those did not on the basis of sexual orientation: only $25.8 \%$ of heterosexuals had already done a first HIV test versus $91.6 \%$ of homosexuals / lesbians who had already done so. The bisexuals who did the HIV test in the past are $42.42 \%$. Of the subjects involved in the test, $57.7 \%$ preferred the modality offered by the Association, $39.80 \%$ were indifferent to the choice to perform the test between hospital and association and only $2.49 \%$ preferred the offer of the test at the facility hospital. Respondents stated that in the last 12 months they did not decide to avoid having sex (including oral) with a seropositive person in $23.5 \%$ of cases, while most of the interviewees did not know the serological status of their partners $(76,5 \%)$. Only $18 \%$ of the sample never avoided having sex with a partner knowing he was HIV 
positive. There are no correlations between gender, sex, sexual orientation, nationality or number of partners in the last year and decision to have sex (including oral) with a partner knowing that he/she is HIV +.

\section{Efficiency and Effectiveness of the Campaign}

The evaluation process requires a series of indicators that are more or less easy to reach, the campaign justifies its effectiveness and prospective efficiency through a series of already observable results. The subjects to be reached were defined in the design phase of the campaign based on the statistical and literature elements previously reported. The campaign has been shared on social networks both by the City of Turin - Youth Office and on the dedicated section on HIV and MST at the Help Desk (receiving an average of 8,694,236 visits a year) and on the institutional page of the Association www.odvcasarcobaleno.it and social associative managed (Facebook and twitter). The poster campaign has also seen the diffusion through a national newspaper called "Repubblica" with a greater diffusion of the initiative and the institutional message linked to 1 December 2018 (Repubblica, 2018). The communication activated by the Association has had direct impact on the more than 500 members present in Casa Arcobaleno (Seat since 2012 of 18 LGBTQ associations and rights protection in a building owned by the City of Turin) through the various member associations and also had an impact on the entire citizenship through the communication campaign carried out in collaboration with the City of Turin. From the week of December 1st, World Day for Combating HIV and AIDS, 220 posters (dimensions $140 \mathrm{~cm} * 200 \mathrm{~cm}$ ) have been posted on the municipal territory of the City of Turin. The campaign created two changes in the message to better reach users. Therefore, during 2018, residents within the City reached by the poster campaign are approximately 884,733 .

The number of views obtained in the sharing of the article published by the Republic relating to the association initiative has reached 17,000 views with 208 direct interactions on the association's social page. In the first quarter following the creation and posting of the campaign there is a $60 \%$ increase in the number of accesses to testing recorded compared to the previous period, also defining an effectiveness in terms of results.

The effects of the campaign have influenced the perception and municipal policies, the campaign based on data from a community-based project has sensitized the Councilor for Equal Opportunities and for the families of the City of Turin in the design phase and contents by directing the future actions of the administration in favour of prevention activities on the territory held by associations. In particular, a continuous communication between the municipal offices and the community-based service has allowed a continuity in relation to the exchange of social and epidemiological statistical information by addressing policies and campaigns with new projects in the programmatic plan.

The Piedmont Region, owner of health promotion campaigns, has welcomed the structure related to the design of the campaign by proposing to the Regional Council the financing of the next communication activities (the project has been accepted in the Regional Council of Associations for the Prevention Associations of HIV and AIDS). The rules on prevention of the territory have not changed as they already include community-based testing activities. The involvement of a volunteer association that performs rapid HIV and syphilis community-based tests allows, in addition to the immediate achievement of the real need, a series of positive effects on the administration and on the community that have immediate repercussions through the campaign itself. The first concerns the return of users who test to the association; after receiving the information and the service, according to our results, users usually go back a second and third time to the community-based service or, when not possible, to the hospital. The community-based preference allows informal messages also linked to the fight against the stigma that is immediately implemented in the risk assessment questionnaires and transmitted to the population through the campaign to combat the stigma of HIV + people. The planning and printing of the campaign, in addition to reducing of production costs, increases the range and speed of production of a campaign of this type. The association is able to overcome the problem related to the bureaucratization of public administrations, specifically the association has printed the communication campaign in two months, the same act according to regulation and capacity of liquidation would have foreseen a higher amount of months losing of effectiveness and efficiency (Osborne, 2010; Osarenkhoe \& Bennani, 2007, Andrews \& Entwistle, 2010; Denhardt, R. B. \& Denhardt, J. V., 2000). In addition, in order to reduce production times by increasing the effectiveness of the campaign that can be linked to the World day for the fight against HIV, the Association has anticipated the financial resources necessary for its realization, resources that even with the advance that the city could grant, between deliberations and extensions, they were not collected within the deadline set for the conclusion of the campaign. Efficacy is also demonstrated by the number of people who prefer the HIV test administered on the territory compared to the hospital context $57.71 \%$ or to those subjects for which testing in the hospital context or in a community-based service is unimportant $39.80 \%$. This data is also confirmed by the fact that the community testing service has managed to attract a percentage of people who have never tested 
themselves in their own life and who prefer this service due to different access times (Brescia \& Iannaci; 2019; Brescia et al., 2019). Efficiency is also guaranteed through the associative and regional protocols that provide for a close connection with the reference hospital. In fact, the positives recorded were confirmed by the hospital to which the subject tested was received with preferential method thanks to the release by the association of a cover letter as required by the protocol of agreement between the hospital and the region and by regional law.

\section{Evidence and Conclusion}

The analysis conducted allowed the construction of an effective communication campaign built on actual elements collected. The analysis of the literature and similar projects already activated on the territory have provided the starting elements on which to define the campaign. The highlight makes it possible to demonstrate, through a logical process, that a campaign to communicate and prevent HIV and the stigma of HIV + people that involves both public institutions and community-based non-profit organizations active in the area leads to advantages regarding efficiency, effectiveness and appropriateness of communication. In particular, the triangulation between the Municipality, the Equal Opportunities Department, the Prevention Health Presidium with a non-profit, community-based organization active for years in terms of HIV testing, is able to reduce time, costs, and impact of the message while increasing the outcomes of the awareness campaign. However, it is still difficult to define the effective reduction of the level of stigma and therefore of well-being associated with the campaign and the related local activities without effective assessment tools in the territory. The authors are aware of the inadequacy of a single tool to effectively reduce the stigma and affect the previous education but raising awareness of the issue through a communication campaign can also be appropriate for this purpose. Further institutional and associative activities will certainly be necessary to achieve the ardent aim of a change in behaviour and greater well-being of the community. The analysis conducted refers only to one case. The limitation of the analysis also focuses on the absence of factors and variables that can further influence the success and failure of the communication campaign and its implementation. Which political propensity and guidelines for institutional overlaps, parallel communication campaigns and prevention activities carried out independently by healthcare facilities. Future research could focus on indicators and tools to detect the stigma to use these indicators to measure the relapse process of a prevention campaign.

\section{Acknowledgments}

We are grateful for the first review provided by Prof. Renato Hübner Barcelos Assistant Professor at the Department of Marketing, Ecole des Sciences de la Gestion - UQÀM, Montréal, Canada. We also thank Dr. Thomas Robin of the School of Medicine, Department of Public Health Sciences, University of Turin for the language review.

\section{References}

Andreasen, A. R. (1995). Marketing social change: Changing behavior to promote health, social development, and the environment (p. 101). San Francisco: Jossey-Bass. https://doi.org/10.2307/3151867

Andreasen, A. R. (2012). Rethinking the relationship between social/nonprofit marketing and commercial marketing. Journal of Public Policy \& Marketing, 31(1), 36-41. https://doi.org/10.1509/jppm.09.035

Andrews, R., \& Entwistle, T. (2010). Does cross-sectoral partnership deliver? An empirical exploration of public service effectiveness, efficiency, and equity. Journal of Public Administration Research and Theory, 20(3), 679-701. https://doi.org/10.1093/jopart/mup045

Atusingwize, E., Lewis, S., \& Langley, T. (2015). Economic evaluations of tobacco control mass media $\begin{array}{lllll}\text { campaigns: a systematic review. Tobacco Control, 24(4), 320-327. } & \text { a }\end{array}$ http://doi.org/10.1136/tobaccocontrol-2014-051579

Austin, E. W., \& Pinkleton, B. E. (2015). Strategic public relations management: Planning and managing effective communication campaigns. Routledge. https://doi.org/10.4324/9781315754833

Bavinton, B. R., Pinto, A. N., Phanuphak, N., Grinsztejn, B., Prestage, G. P., Zablotska-Manos, I. B., \& Bloch, M. (2018). Viral suppression and HIV transmission in serodiscordant male couples: an international, prospective, observational, cohort study. The Lancet HIV, 5(8), e438-e447. https://doi.org/10.1016/s2352-3018(18)30132-2

Benbasat, I. (1984). An analysis of research methodologies. In F. Warren McFarlan (Ed.), The Information systems research challenge (pp. 47-85). Boston, MA: Harvard Business School Press.

Bert, F., Gualano, M. R., Biancone, P., Brescia, V., Camussi, E., Martorana, M., \& Siliquini, R. (2018). Cost-effectiveness of HIV screening in high-income countries: A systematic review. Health Policy. 
https://doi.org/10.1016/j.healthpol.2018.03.007

Bert, F., Gualano, M. R., Biancone, P., Brescia, V., Camussi, E., Martorana, M., ... \& Siliquini, R. (2018). HIV screening in pregnant women: A systematic review of cost - effectiveness studies. The International Journal of Health Planning and Management, 33(1), 31-50. https://doi.org/10.1002/hpm.2418

Biancone, P., Secinaro, S., \& Brescia, V. (2016). The Popular Financial Reporting: Focus on Stakeholders-The first European Experience. International Journal of Business and Management, 11(11), 115-125. https://doi.org/10.5539/ijbm.v11n11p115

Brescia, V., \& Iannaci, D. (2019, January 4). BILANCIO SOCIALE - ODV CASA Arcobaleno Anno 2018. Zenodo. http://doi.org/10.5281/zenodo.2531826

Brescia, V., Tradori, V., Radwan, M., \& Bert, F. (2019). Risk Management and Analytical Accounting Approach in Use of the HIV Rapid Tests in the Hospital: The Case of the Amedeo di Savoia. In The Future of Risk Management, Volume I (pp. 175-195). Palgrave Macmillan, Cham. https://doi.org/10.1007/978-3-030-14548-4_8

Breveglieri, M., Bosa, M., \& Valerio, B. (2017). Valutazione Del Rischio. Zenodo. http://doi.org/10.5281/zenodo.2551114

Carroll, A. B., \& Shabana, K. M. (2010). The business case for corporate social responsibility: A review of concepts, research and practice. International Journal of Management Reviews, 12(1), 85-105. https://doi.org/10.1111/j.1468-2370.2009.00275.x

Catania, J. A., Kegeles, S. M., \& Coates, T. J. (1990). Towards an understanding of risk behavior: An AIDS risk reduction model (ARRM). Health Education Quarterly, 17(1), 53-72. https://doi.org/10.1177/109019819001700107

Cates Jr, W., Chesney, M. A., \& Cohen, M. S. (1997). Primary HIV infection--a public health opportunity. American Journal of Public Health, 87(12), 1928-1930. https://doi.org/10.2105/ajph.87.12.1928

Cohen, J. (2001). Defining identification: A theoretical look at the identification of audiences with media character. Mass Communication \& Society, 4, 245-264. https://doi.org/10.1207/S15327825MCS0403_01

Cho, H., \& Salmon, C. T. (2006). Unintended effects of health communication campaigns. Journal of communication, 57(2), 293-317. https://doi.org/10.1111/j.1460-2466.2007.00344.x

Chung, A. H., \& Slater, M. D. (2013). Reducing stigma and out-group distinctions through perspective-taking in narratives. Journal of Communication, 63(5), 894-911. https://doi.org/10.1111/jcom.12050

Cleemput, I., Neyt, M., Thiry, N., De Laet, C., \& Leys, M. (2008). Threshold values for cost-effectiveness in health care. Health technology assessment (HTA). KCE Reports B, 100. https://doi.org/10.1017/s0266462310001194

Corrigan, P. W. (2011). Best practices: Strategic stigma change (SSC): Five principles for social marketing campaigns to reduce stigma. Psychiatric Services, 62(8), 824-826. https://doi.org/10.1176/appi.ps.62.8.824

Corrigan, P. W., Powell, K. J., \& Al-Khouja, M. A. (2015). Examining the Impact of Public Service Announcements on Help Seeking and Stigma. The Journal of Nervous and Mental Disease, 203(11), 836-842. https://doi.org/10.1097/nmd.0000000000000376

CNAIDS. (2016). Ministry of Health and Higher Institute of Health (CNAIDS). HIV infection and drug use: determination of ECDC indicators (European Center for Disease Control) for prevention. Summary of the report by the Istituto Superiore di Sanità - National AIDS Center. Retrieved from https://www.google.it/url?sa=t\&rct=j\&q=\&esrc=s\&source=web\&cd=5\&cad=rja\&uact=8\&ved=2ahUKEwjI -4iDnL3fAhUi4YUKHW-cDT0QFjAEegQIBRAC\&url=http\%3A\%2F\%2Fwww.salute.gov.it\%2Fimgs\%2F C_17_pubblicazioni_2661_allegato.pdf\&usg=AOvVaw1BZGyf_4ZV9O6DFmqle9DO

Coates, T. J., Richter, L., \& Caceres, C. (2008). Behavioural strategies to reduce HIV transmission: how to make them work better. The Lancet, 372(9639), 669-684. https://doi.org/10.1016/s0140-6736(08)60886-7

Coffman, J. (2002). Public communication campaign evaluation: an Environmental Scan of Challenges, Criticisms, Practice, and Opportunities. Prepared for the Communications Consortium Media Center by the Harvard Family Research Project in May 2002.

Craig Lefebvre, R., \& Flora, J. A. (1988). Social marketing and public health intervention. Health Education Quarterly, 15(3), 299-315. https://doi.org/10.1177/109019818801500305 
Denhardt, R. B., \& Denhardt, J. V. (2000). The new public service: Serving rather than steering. Public Administration Review, 60(6), 549-559. https://doi.org/10.1111/0033-3352.00117

DeJong, R. Cameron Wolf, S. Bryn Austin, W. (2001). US federally funded television public service announcements (PSAs) to prevent HIV/AIDS: A content analysis. Journal of Health Communication, 6(3), 249-263. https://doi.org/10.1080/108107301752384433

Denzin, N. K., \& Lincoln, Y. S. (1994). Handbook of qualitative research. Thousand Oaks \& London: Sage.

ECDC (2009). Mapping of HIV/STI behavioural surveillance in Europe. 978-92-95009-86-8European Centre for Disease prevention and Control (ECDC) (2010). Stockholm: HIV Testing.

ECDC (2010). GUIDANCE HIV testing: increasing uptake and effectiveness in the European Union.

Eisenhardt, K. M. (1989). Building theories from case study research. Academy of Management Review, 14, 532-550. https://doi.org/10.5465/amr.1989.4308385

Federfarma (2016). Pill of the day after, survey by Federfarma Verona: consumption surge. Retrieved from https://www.federfarma.it/Edicola/Filodiretto/VediNotizia.aspx?id=18050

Frascara, J., Meurer, B., van Toorn, J., \& Winkler, D. (1997). User-centred graphic design: Mass communication and social change. CRC Press.

Frati, A., \& Cordone, M. N. (2002). Le campagne informativo-educative sull'AIDS del Ministero della Salute 1988-2002. Boll Farmacodip e Alcoolis, 25(1-2), 11-18.

Geller, E. S. (1989). Applied behavior analysis and social marketing: An integration for environmental preservation. Journal of social issues, 45(1), 17-36. https://doi.org/10.1111/j.1540-4560.1989.tb01531.x

Glaser, B. G., \& Strauss, A. L. (1967). The discovery of grounded theory: strategies for qualitative theory. New Brunswick: Aldine Transaction. https://doi.org/10.4324/9780203793206-1

GBS (2013). GBS 2013 Standard-Principles of preparation of the social report. Retrieved from http://www.gruppobilanciosociale.org/pubblicazioni/standard-gbs-2013-principi-di-redazione-del-bilancio-s ociale/

Goffman, E. (1963). Stigma: notes on the management of spoiled identity. Englewood Cliffs, NJ: Prentice-Hall

Hatziandreu, E. J., Sacks, J. J., Brown, R., Taylor, W. R., Rosenberg, M. L., \& Graham, J. D. (1995). The cost effectiveness of three programs to increase use of bicycle helmets among children. Public health reports, 110(3), 251-9. https://doi.org/10.1016/s0022-4375(96)00036-9

Harris, J. M., Ciorciari, J., \& Gountas, J. (2018). Public health social media communications and consumer neuroscience. Cogent Psychology, 5(1), 1434058. https://doi.org/10.1080/23311908.2018.1434058

HIV in Europe Secretariat (2012). HIV Indicator Conditions: Guidance for Implementing HIV Testing in Adults in Health Care Settings. October 2012. Retrieved from https://issuu.com/kandrup/docs/chip_guidance?e=4233206/1998749

HIV testing in Europe (2004). Monitoring implementation of the Dublin Declaration on partnership to fight HIV/AIDS in Europe and Central Asia. Progress report.

Holtgrave, D. R., Wunderink, K. A., Vallone, D. M., \& Healton, C. G. (2009). Cost- Utility Analysis of the National truth. Campaign to Prevent Youth Smoking. American Journal of Preventive Medicine, 36(5), 385-388. http://doi.org/10.1016/j.amepre.2009.01.020

Hornik, R. (2002). Public Health Communication: Evidence for Behavior Change. Routledge. https://doi.org/10.4324/9781410603029

Hurley, S. F., \& Matthews, J. P. (2008). Cost-effectiveness of the Australian National Tobacco Campaign. Tobacco Control, 17(6), 379-384. http://doi.org/10.1136/tc.2008.025213

ISTAT (2015). How women's lives change. Letture statistiche - Temi. Retrieved from https://www.istat.it/it/archivio/176768 (Accessed: 11/01/2019)

Liu, P., Tang, Z., Lan, G., Zhu, Q., Chen, H., You, Y., \& Liao, L. (2018). Early antiretroviral therapy on reducing HIV transmission in China: strengths, weaknesses and next focus of the program. Scientific reports, $8(1)$, 3431. https://doi.org/10.1038/s41598-018-21791-2

Yadav, A. K., Gupta, H., Vaz, L. S., \& Yadav, J. (2018). Human immunodeficiency virus, sexually transmitted disease awareness and condom usage among long-distance internal truck drivers in Pune, India. HIV \& 
AIDS Review. International Journal of HIV-Related Problems, 17(1), 40-48.

Yin, R. K. (1994). Case study research: Design and methods. London: Sage.

Kosenko, K. A. (2011). The safer sex communication of transgender adults: Processes and problems. Journal of Communication, 61(3), 476-495. https://doi.org/10.1111/j.1460-2466.2011.01556.x

Kotler, P. (1971). What consumerism means for marketers. Harvard Business Review, 50(3).

Kotler, P., \& Roberto, E. L. (1989). Social Marketing: Strategies for Changing Public Behavior. Simon and Shuster.

Kotler, P., \& Zaltman, G. (1971). Social marketing: an approach to planned social change. The Journal of Marketing, 3-12. https://doi.org/10.1177/002224297103500302

Kotler, P., Roberto, N., \& Lee, N. (2002). Social marketing-improving the quality of life. Thousand Oaks, CA: Sage. https://doi.org/10.1093/pubmed/fdg040

Lazarus, J. V., Hoekstra, M., Raben, D., Delpech, V., Coenen, T., Lundgren, J. D., \& HIV in Europe Initiative Steering Committee. (2013). The case for indicator condition - guided HIV screening. HIV medicine, 14(7), 445-448.

Leonard-Barton, D. (1990). A dual methodology for case studies: Synergistic use of a longitudinal single site with replicated multiple sites. Organization science, 1(3), 248-266. https://doi.org/10.1287/orsc.1.3.248

Link, B. G., \& Phelan, J. C. (2001). Conceptualizing stigma. Annual review of Sociology, 27(1), 363-385. https://doi.org/10.1146/annurev.soc.27.1.363

Loss, J., Lindacher, V., \& Curbach, J. (2014). Online social networking sites - a novel setting for health promotion? Health \& Place, 26, 161-170. https://doi.org/10.1016/j.healthplace.2013.12.012

Machado, A. T., Antunes, A. C., \& Miranda, S. (2016). Social marketing through communication campaigns: the Portuguese Association for Victim Support Case (APAV). Revista Portuguesa de Marketing, 19(36), 7-22.

McColl, E. R., Kojovic, D., \& Piquette - Miller, M. (2018). Battling the HIV/AIDS Epidemic: Triumphs and Barriers. Clinical Pharmacology \& Therapeutics, 104(6), 1042-1046. https://doi.org/10.1002/cpt.1202

McKenzie-Mohr, D., \& Smith, W. (1999). Fostering sustainable development. An introduction to community-based social marketing. Canadá: New Society Publishers. https://doi.org/10.1037//0003-066x.55.5.531

Niederdeppe, J., Davis, K. C., Farrelly, M. C., \& Yarsevich, J. (2006). Stylistic features, need for sensation, and confirmed recall of national smoking prevention advertisements. Journal of Communication, 57(2), 272-292. https://doi.org/10.1111/j.1460-2466.2007.00343.x

Oppenheim, A. N. (2000). Questionnaire design, interviewing and attitude measurement. Bloomsbury Publishing. https://doi.org/10.2307/3172892

Osarenkhoe, A., \& Bennani, A. E. (2007). An exploratory study of implementation of customer relationship management strategy. Business Process Management Journal, 13(1), 139-164. https://doi.org/10.1108/14637150710721177

Osborne, S. P. (Ed.). (2010). The new public governance: Emerging perspectives on the theory and practice of public governance. Routledge. https://doi.org/10.4324/9780203861684

Piedmont Region. (2016). Resolution n 24314A1409A. Politiche di offerta del test HIV in Piemonte -policy of HIV test offer in Piedmont.

Rainero, C., \& Brescia, V. (2016). Corporate Social Responsibility» and «Social Reporting»: The Model of Innovation «Piedmont Method. International Journal Series in Multidisciplinary Research (IJMR), 2(3), $18-40$.

Safier, L. Z., \& Sauer, M. V. (2017). Fertility care interventions should be provided as the first line options for $\mathrm{HIV}+$ serodiscordant couples who desire children in settings with affordable access to care, regardless of their fertility status. Journal of the International AIDS Society, 20, 21294. https://doi.org/10.7448/ias.20.2.21294

Seremi, C., Pasqualini, D., \& Lombardi, C. (2018). Di Pietrantonj Infezioni sessualmente trasmesse in Piemonte.

Shi, J., Poorisat, T., \& Salmon, C. T. (2018). The use of social networking sites (SNSs) in health communication campaigns: review and recommendations. Health communication, 33(1), 49-56. 
https://doi.org/10.1080/10410236.2016.1242035

Signorelli, A., Odone, A., Bianco, D., Di Vivo, N., \& Bevere, F. (2016). La spesa per la prevenzione in Italia (2006-2013): analisi descrittiva, trend regionali e confronti internazionali. Epidemiol Prev, 40(5), 374-80.

Silverman, D. (2005). Doing qualitative research. London: Sage. https://doi.org/10.1177/14687941100100030605

Singh, J., Goyal, G., \& Gill, R. (2019). Use of neurometrics to choose optimal advertisement method for omnichannel business. Enterprise Information https://doi.org/10.1080/17517575.2019.1640392

Struckman - Johnson, D., \& Struckman - Johnson, C. (1996). Can You Say Condom?: It Makes a Difference in Fear - Arousing AIDS Prevention Public Service Announcements 1. Journal of Applied Social Psychology, 26(12), 1068-1083. https://doi.org/10.1111/j.1559-1816.1996.tb01125.x

Sullivan, A. K., Raben, D., Reekie, J., Rayment, M., Mocroft, A., Esser, S., \& Grzeszczuk, A. (2013). Feasibility and effectiveness of indicator condition-guided testing for HIV: results from HIDES I (HIV indicator diseases across Europe study). PloS one, 8(1), e52845. https://doi.org/10.1371/journal.pone.0052845

Tradori, V., Biancone, P., Cardaci, A., \& Brescia, V. (2017a). Legislazione, politiche e organizzazione di centri community based di diagnosi e prevenzione dell'HIV nella Regione Piemonte. Sanità Pubblica E Privata, 4, 37-51.

Tradori, V., Biancone, P., Secinaro, S., \& Brescia, V. (2017). Legislation, policies and organization of community- based Centers for HIV diagnosis and prevention in Piedmont Region. International Journal of Management Sciences And Business Research, 6(11), 17-27.

UNAIDS (2017). Global AIDS Monitoring 2018. Indicators for monitoring the 2016 United Nations Political Declaration on Ending AIDS.

Vanable, P. A., Ostrow, D. G., McKirnan, D. J., Taywaditep, K. J., \& Hope, B. A. (2000). Impact of combination therapies on HIV risk perceptions and sexual risk among HIV-positive and HIV-negative gay and bisexual men. Health psychology, 19(2), 134. https://doi.org/10.1037//0278-6133.19.2.134

Varcoe, J. (2004). Assessing the effectiveness of social marketing. In ESOMAR Public Sector Research Conference.

Varghese, B., Maher, J. E., Peterman, T. A., Branson, B. M., \& Steketee, R. W. (2002). Reducing the risk of sexual HIV transmission: quantifying the per-act risk for HIV on the basis of choice of partner, sex act, and condom use. Sexually Transmitted https://doi.org/10.1097/00007435-200201000-00007

Waitt, C., Low, N., Van de Perre, P., Lyons, F., Loutfy, M., \& Aebi-Popp, K. (2018). Does U= U for breastfeeding mothers and infants? Breastfeeding by mothers on effective treatment for HIV infection in high-income settings. The Lancet HIV, 5(9), e531-e536. https://doi.org/10.1016/s2352-3018(18)30098-5

Weinreich, N.K. (2018) What is Social Marketing? Retrieved from https://www.researchgate.net/profile/Nedra_Weinreich/publication/240412155_What_is_Social_Marketing/ links/56e0950508aec4b3333d10df/What-is-Social-Marketing.pdf

Weller, S. C. (1993). A meta-analysis of condom effectiveness in reducing sexually transmitted HIV. Social Science \& Medicine, 36(12), 1635-1644. https://doi.org/10.1016/0277-9536(93)90352-5

Weller, S. C., \& Davis - Beaty, K. (2002). Condom effectiveness in reducing heterosexual HIV transmission. Cochrane Database of Systematic Reviews, (1). https://doi.org/10.1002/14651858.cd003255

Wingood, G. M., \& DiClemente, R. J. (2000). Application of the theory of gender and power to examine HIV-related exposures, risk factors, and effective interventions for women. Health Education \& Behavior, 27(5), 539-565. https://doi.org/10.1177/109019810002700502

Woodson, E., Goldberg, A., Michelo, C., Basu, D., Tao, S., Schinazi, R., \& Hunter, E. (2018). HIV transmission in discordant couples in Africa in the context of antiretroviral therapy availability. AIDS, 32(12), 1613-1623. https://doi.org/10.1097/qad.0000000000001871

Workowski, K. A., \& Bolan, G. A. (2015). Sexually transmitted diseases treatment guidelines, 2015. MMWR. Recommendations and reports: Morbidity and mortality weekly report. Recommendations and reports, 64(RR-03), 1. 
World Health Organization (WHO), (2010). Scaling up HIV testing and counseling in the WHO European Region as an essential component of efforts to achieve universal access to HIV prevention, treatment, care and support.

World Health Organization (WHO). (2015). Geneva: Consolidated guidelines on HIV testing services.

World Health Organization (WHO). (2015a). Geneva: What's new in HIV monitoring.

World Health Organization (WHO). (2018). Report on global sexually transmitted infection surveillance 2018.

Wright, J. (2018). Application of Narrative Principles to Effectively Communicate Through Graphic Design.

Xu, X., Alexander, R. L., Simpson, S. A., Goates, S., Nonnemaker, J. M., Davis, K. C., \& McAfee, T. (2015). A Cost-Effectiveness Analysis of the First Federally Funded Antismoking Campaign. American Journal of Preventive Medicine, 48(3), 318-325. http://doi.org/10.1016/j.amepre.2014.10.011

\section{Copyrights}

Copyright for this article is retained by the author(s), with first publication rights granted to the journal.

This is an open-access article distributed under the terms and conditions of the Creative Commons Attribution license (http://creativecommons.org/licenses/by/4.0/). 